Culture et histoire dans l'espace roman

\title{
El año del desierto de Pedro Mairal: una patria deconstruida
}

\section{Victoria Liendo}

\section{(2) OpenEdition}

1 Journals

Edición electrónica

URL: https://journals.openedition.org/cher/12426

DOI: 10.4000/cher.12426

ISSN: 2803-5992

Editor

Presses universitaires de Strasbourg

Edición impresa

Fecha de publicación: 30 junio 2012

Paginación: 203-211

ISBN: 978-2-35410-046-9

ISSN: $1968-035 X$

\section{Referencia electrónica}

Victoria Liendo, «El año del desierto de Pedro Mairal: una patria deconstruida», reCHERches [En línea], 8| 2012, Publicado el 21 febrero 2022, consultado el 23 febrero 2022. URL: http://

journals.openedition.org/cher/12426; DOI: https://doi.org/10.4000/cher.12426

\section{(c) (i) (2)(2)}

Ce(tte) œuvre est mise à disposition selon les termes de la Licence Creative Commons Attribution Pas d'Utilisation Commerciale - Partage dans les Mêmes Conditions 4.0 International. 


\title{
El año del desierto de Pedro Mairal: una patria deconstruida
}

\author{
VICTORIA LIENDO \\ Université Paris 8 - Vincennes Saint Denis
}

E

año del desierto, segunda novela de Pedro Mairal, fue publicada en el 2005. El relato empieza con un capítulo corto en primera persona del presente: una mujer nos cuenta que vive en algún lugar de Europa donde habla otra lengua que no es su lengua natal. Nos dice que trabaja en una biblioteca y que en su tiempo libre despliega mapas donde todavía existe la ciudad en que nació. Recorre con el dedo las calles desaparecidas en el intento imposible de querer volver a tocarlas. El lector descubre, entonces, que hubo un país del que ahora sólo queda una mujer. Su voz es el resto único de una historia y una tierra que apenas figura en mapas viejos. Es ahí donde nace la narración, en el recuerdo entendido como una tarea, como un deber mayor $y$, a la vez, un deber frustrado desde el principio porque evocar nunca es recuperar, porque no hay conjuro contra lo que ya está perdido. Sin embargo, a pesar del fracaso, o desde el fracaso, empieza la narración.

La novela es el recorrido sensible de tres buenas ideas. Una de ellas es contar la historia argentina en el sentido inverso. Para decirlo con una imagen: imagínense que están mirando por televisión los eventos de la crisis del 2001, imaginen estar viendo los saqueos, la policía montada, la gente corriendo desesperada sin saber hacia dónde o para qué, imagínense que en ese momento la imagen se congela y entonces, con la velocidad alucinatoria del botón rewind, toda la historia argentina empieza a contarse hacia atrás, desde la debacle histórica más actual hasta el principio del desierto, cuando 
el vacío del territorio era la más grande amenaza contra la cual debía batirse el argentino. Narrar el tiempo al revés es contar la historia nacional como el relato de un fracaso: es la Argentina involutiva, el país del derrumbe y de la desintegración para el cual el pasado se convierte en su único futuro.

El juego con el tiempo no se limita nada más que a cambiarle el sentido de adelante para atrás. La propuesta es también condensar el devenir histórico de dos siglos de nación en trescientos sesenta y cinco días de vida. Es el relato de un solo año en el que la Argentina retrocede hasta desaparecer, pasando por todos sus avatares, los más ancestrales y los más contemporáneos. Aquí podemos adelantar una clave de lectura de la que nos serviremos más adelante: ejecutar tal condensación es trabajar con una idea de repetición, es decir, aquello que a través de los años en sus diferentes formas siempre regresa, insiste, se metamorfosea sin perder una esencia primera, trascendente.

No se trata de cualquier año sino de un año en la vida de María Valdés. El relato empieza el mismo día que ella, personaje principal, cumple veintitrés. María, voz narradora y heroína, se define por ser un personaje sin atributos, el testigo más neutral de todas las peripecias que irá atravesando, peripecias en las que su propia vida se irá convirtiendo en el escenario de una cosa mayor que la sobrepasa y la devora: la vida del país.

¿Qué consecuencias tiene contar la historia al revés? Pensemos en el ejemplo del bandoneón, instrumento que inventan los alemanes para hacer música religiosa a fines del siglo XIX. En esa misma época, marineros e inmigrantes lo traen en los barcos que llegan al puerto de Buenos Aires donde el bandoneón va a encontrarse con su verdadero destino: de esos sonidos antes sacros nace entonces el tango inmortal. En la novela, el proceso va a ser el inverso: un tanguero oscurecido porque el tango ya no existe pasa su tiempo penando en prostíbulos hasta que un día, habiendo tomado más de lo que le permitían sus bolsillos, deja el bandoneón como forma de pago: «[...] y ahí quedó el instrumento, dando vueltas hasta que se lo vendieron a un carpintero alemán que lo quería para su hermano que tocaba música sacra en las iglesias de Heidelberg» (Mairal 2010: 166). En la ficción de Mairal ya no es unívoco el sentido de la historia, ya no es de Alemania que vino el instrumento ni radicalmente de Buenos Aires que llegó hasta Alemania sino que esa relación de causa-consecuencia, esa relación histórica entre un antes y un después se pierde en el camino del pasado reescrito como una nueva forma del futuro. El resultado de esta operación 
narrativa es finalmente perder el concepto de origen, confundirlo al punto de que ya no pueda ser rastreado.

¿Qué significa condensar doscientos años en uno solo? Cuando le preguntaron en una entrevista a Martínez Estrada por qué había escrito Radiografía de la pampa, él respondió con una anécdota. Era la revolución del 30, estaba en la calle con un amigo y de repente al oír el grito de "u-ribuuu-ru" le pareció estar escuchando "i-ri-goooo-yen": «Tenía recuerdo aún fresco de las fiestas del Centenario, y de súbito tuve la impresión de que me encontraba retrotraído a veinte años atrás, como si ni yo ni lo que nos rodeaba hubiesen cambiado. El tiempo era un sueño» (Martínez Estrada 1969: 131). El escritor parece estar hablando de cierta insistencia en la historia argentina que sucede en la calles y en los libros: «He tratado de configurar un diagrama con los invariantes históricos que creí hallar en el Facundo y además en las Bases, Ojeada retrospectiva y en los escritos doctrinarios de Moreno y Monteagudo» (134).

«Los invariantes históricos» podrían pensarse como aquello que siempre regresa. La novela de Mairal se inscribe en este impulso por captar lo que se repite. Para hacer entrar tantos años de historia en un solo año de vida, El año del desierto recurre al sincretismo ingenioso en el que la línea recta del tiempo que va hacia atrás va condensando -siempre dentro del eje de lo verosímil- figuras sociales que están construidas en la convivencia de diferentes épocas y culturas, como si un montón de láminas transparentes fueran formando un solo dibujo múltiple. Veamos un ejemplo: el indio que aparece en este texto no es aquel que describía Mansilla en 1870 sino una mezcla de indio y de "villero", es decir, un sujeto social contemporáneo que podría pensarse como su nuevo avatar. Se trata de un indio que lleva un tatuaje de la Virgen en el pecho, shorts de fútbol y ojotas de vestuario; un indio que en su botín cuenta con «botellas, sillas, una bañadera, una bolsa de palos de golf, una bicicleta rosa, valijas, platos, machetes, un teclado eléctrico» (Mairal 2010: 246). Con su lengua pasa otro tanto: «Biniguach» es vení guacho, «bocataí nomá» es vos quedate ahí nomás, «cate pío guasch», quedate piola guacho. «Era cuestión de hacerse el oído», dice el texto.

Eso que sobrevive en esta suerte de traducción de una temporalidad a otra o actualización del pasado ad hoc juega con la tradición que funda Sarmiento y retoma Martínez Estrada, como si una forma de nombrar lo propio fuera recuperar aquellos rasgos que estuvieron desde el principio de los tiempos argentinos, cierta "esencia", la repetición binaria que persiste 
de una época a otra, civilización y barbarie, criollos e indios, unitarios y federales, radicales y peronistas, "puentistas y tuneleros".

La relación entre vida privada e historia nacional nos resulta otro punto fértil de la novela y la tradición en la que se inscribe. En las ficciones de Borges aparece una y otra vez ese instante mínimo en el que se revela todo el sentido de la existencia de un sujeto. No es casual que esa revelación, en la que se cifra el destino de cada hombre, esté siempre atravesada por su vínculo con la nacionalidad. Tampoco que la nacionalidad, de una manera o de otra, se represente a partir del espacio, es decir, el desierto. Tadeo Isidoro Cruz comprende en el grito del chajá la verdadera forma de su destino. La clave tal vez no esté en lo visible, lo que el final del cuento devela de golpe (luchar al costado de Martín Fierro) sino en ese pájaro, justamente, que desde Echevarría representa la pampa.

La clave está en el título de la novela, más exactamente en la palabra «desierto». No es el año del país ni el año de los veintitrés de María, sino el año del desierto, espacio en donde María y el país se convierten en uno solo, donde se hunden y se fundan simultáneamente. En este sentido, podemos decir que la novela de Mairal se adentra en las viejas rutas de la tradición que desde el Facundo intenta dar cuerpo y sentido a la noción de identidad nacional.

En el libro de Sarmiento el vínculo originario se da entre hombre y tierra. El determinismo geográfico, corriente filosófica que reivindica, se ocupa de cuestionar el concepto de libertad a partir de una lógica positivista en la que el espacio funciona como molde formador del sujeto. En el primer capítulo, Sarmiento intenta dar cuenta de "los aspectos físicos de la República argentina" y "los caracteres, hábitos e ideas que engendra" (Sarmiento 2000: 5). El espacio engendra, el desierto engendra. La nación nace parida por el desierto. Ahora bien, ¿qué es el desierto?

Adolfo Prieto, en su libro Los viajeros ingleses y la emergencia de la literatura argentina, postula una lectura de los textos de la generación del 37 como traducciones de libros extranjeros, proponiendo pensar el origen de lo propio como una irremediable copia alterada de lo ajeno. El mismo Facundo es la importación desordenada de citas y textos europeos y americanos que resemantiza y convierte a lo nacional: el simulacro que late adentro de este gesto genealógico yace justamente en el hecho de que Sarmiento, cuando escribe el Facundo, no conoce la pampa sino los relatos que otros, los viajeros ingleses, hicieron de ella. El trabajo que hace con esos textos es, al mismo tiempo, arbitrario y operativo a sus fines ideológicos. El desierto, desde su 
origen, es un espacio mítico, ficción hecha de ficciones, relato ajeno, lectura salvaje y reescritura bárbara.

Borges, en El escritor argentino y su tradición, va a llevar este mismo pensamiento al plano de la creación literaria. No hace falta, dice, pensar la literatura argentina encerrados en el nacionalismo del color local sino entender que nuestra tradición es la tradición de todo el occidente, tradición tan grande y abundante como el lenguaje mismo, donde ya no hay original y copia sino una gran biblioteca infinita con la que cada uno puede básicamente hacer lo que le dé la gana.

Como dijimos a propósito de Sarmiento, que la tierra determine al hombre, una tierra que es a su vez un cronotopo, una ficción, un mito, es la compleja materia de la que se nutre desde sus orígenes la literatura argentina y su pulsión irrefrenable por construir una nación. En esta tradición literaria se delinea fuertemente una metafísica del destino. De alguna manera, la pregunta que hace eco parece ser, ¿se puede escapar de la fatalidad del desierto? La novela de Mairal se sumerge hasta el fondo en esta tradición.

La narración de la historia nacional se articula en la novela a partir de una estrategia doble. Por un lado, existe un trabajo exhaustivo con lo referencial, la ficción se estructura bajo leyes de la tradición realista donde los «effets de réel» (el nombre propio, las marcas industriales, las referencias históricas y urbanísticas) operan de manera decisiva en la representación de un pasado y su consecuente construcción del mundo. Por el otro, sobre la base de este sistema representativo, se cuelan referencias ficcionales ostentando rasgos tan verosímiles que terminan por confundirse con los verdaderos datos históricos. Podría decirse que en este texto, tan preocupado por la historia y por el tiempo, se superponen dos pulsiones opuestas: la pulsión al rigor historiográfico y la pulsión a lo ahistórico.

$\mathrm{Si}$, por una parte, el relato parece obsesionado con fijar lo que se está perdiendo, dar verdadero testimonio de la historia fáctica, por otra parte se da cuenta de cierta reacción del pueblo argentino frente al cambio incesante que está signada por la negación, por el olvido represivo de lo que era el mundo hace cinco minutos. La gente que atraviesa este año de intemperie no puede sino vivir en el instante, en lo inmediato; aferrada a la pulsión a lo ahistórico, el aquí y ahora se actualiza cada vez como unidad espaciotemporal absoluta, haciendo del olvido una técnica de supervivencia.

- ¿De qué lado está Perón? - pregunté.

Una señora me miró como si estuviera loca. Volví a preguntar a otra gente, pero nadie sabía. Cambié la pregunta: 
-La calle después de Sarmiento, ¿para dónde es?

- ¿Cangallo?- me dijeron.

Le habían cambiado el nombre (Mairal: 104).

- ¿Sabés cuál es el edificio, uno que está antes de cruzar Mitre?

- ¿Cuál Mitre?

-No te hagas la tarada, una cuadra antes de Rivadavia.

-Ésa se llama Calle de la Piedad - me dijo (187).

En este movimiento de borrón y cuenta nueva parece instalarse una modalidad argentina frente a la historia de sus fracasos, una adaptación inércica, sometida: María vive con desesperación cómo la gente se acomoda al desastre, cómo acepta ese destino trágico como un destino personal sin cuestionamientos, un destino que los identifica y los define porque aunque lo padecen no pueden sino elegir:

-¿Tenés familia?

$-\mathrm{No}$

-Yo sí, pero se fueron todos a España.

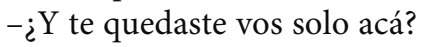

-Sí. Quiero quedarme acá hasta que las cosas mejoren y, si no mejoran, hasta que se termine todo (127).

Esta división entre un afuera y un adentro, lo que parece externo (la respuesta de la gente) y lo que parece interno (la indignación y el hartazgo de María por tener que convertirse en las más variadas y siempre sufrientes versiones de la mujer argentina), empieza a dejar ver algo más, un sentimiento misterioso del que ni siquiera ella va a poder escapar. A lo largo del constante cambio, sobrevive en el texto, como una respiración, cierta religión del desierto, una espiritualidad identitaria que se erige sobre lo que se deshace, que encuentra su aliento en el terror del espacio vacío, devorador, desolado y amenazante.

Cuando Frank, un marinero irlandés, le ofrece sacarla del país y llevarla a Europa, el relato parece encontrar por fin la salvación de María. Sin embargo, cuando el momento llega, leemos: «Si lo seguía me iba a ahogar. Sonaba una campana para embarca. ¿Qué iba a hacer? ¿Qué tenía que hacer? ¿Para qué me iba a quedar en un lugar donde todo se deshacía? Pero el cuerpo parecía querer quedarse, la desintegración era algo mío, el desierto era algo mío» (183).

La oscilación mencionada entre pulsiones antagónicas encarnada en María versus la gente con la que se va topando en su camino existe hasta que irrumpe el desierto, hasta que triunfa la intemperie:

El avance de la intemperie me había hecho sentir que toda la ciudad, a medida que se borraba de la realidad, debía quedar grabada en mi cabeza. 
Yo tenía la obligación (nadie me lo había pedido) de memorizar cada rincón, cada calle, cada fachada, y no dejar que los nuevos terrenos baldíos se superpusieran sobre la nitidez de mi recuerdo y lo borraran. Entrar en el campo me libraba de ese mandato, lo borraba todo de una vez, al menos, en mi cabeza (196-197).

Así, María se va entregando a la fuerza de lo que se llama «tierra adentro»:

Cerré los ojos. Me quedé así un rato largo, entregada a esa voluntad que me era ajena y que me seguía arrastrando de acá para allá, esa fuerza que era algo parecido a Dios, pero también era la desintegración y lo invisible, y también la intemperie y el viento, la soledad de ese lugar vacío, el dios del mundo sin gente. No sé cómo explicarlo. Un yuyo seco doblándose en el viento, algo que nadie ve, un lugar igual a cualquier otro en ese desierto donde hasta los bichos ciegos escarbaban sus cuevas para huir del desamparo del cielo (267).

El lector va descubriendo que eso parece el futuro y es el pasado, esa confusión o fusión de tiempos está hablando de lo que estuvo desde siempre. Lo atemporal es una forma de la eternidad. En un momento, van caminando por el medio de lo que había sido la avenida Las Heras. El personaje recuerda entonces:

Otras veces había sentido lo mismo al cruzar la avenida. Incluso estando todavía los edificios altos, había tenido una sensación de intemperie. Era algo físico, cuando cortaba el semáforo y no pasaban autos ni colectivos, y yo cruzaba mal, por la mitad. Durante un instante, había mucho cielo ahí en medio del asfalto y un viento raso me arremolinaba el pelo. [...] Debajo de la ciudad, siempre había estado latente el descampado (174).

$\mathrm{Al}$ fracaso, que acá tiene el nombre de intemperie, de desierto, lo define un carácter progresivo, devorador, como un océano que le va ganando terreno a la orilla, que se la va comiendo. Lo define, también, una esencia camaleónica, fuerza fatídica o de la naturaleza que va obligando al personaje a atravesar un sinfín de dolorosos avatares, todos sufrientes y esclavos. Sin embargo, a lo largo que la novela avanza y la Argentina se destruye, la intemperie empieza a cobrar otra potencia, a develarse mucho más íntima de lo que nos hubiéramos imaginado, y, por la misma razón, mucho más siniestra: ya no es sólo invasora y externa sino que parece estar aleteando ahí donde late el núcleo central de la identidad argentina. Se trata, nada más ni nada menos, del destino sudamericano, aquel que en el poema conjetural aceptaba Laprida como el instante en que toda su vida, al borde del fin más injusto, se llenaba de sentido: 
Yo que anhelé ser otro, ser un hombre de sentencias, de libros, de dictámenes a cielo abierto yaceré entre ciénagas; pero me endiosa el pecho inexplicable un júbilo secreto. Al fin me encuentro con mi destino sudamericano. A esta ruinosa tarde me llevaba el laberinto múltiple de pasos que mis días tejieron desde un día de la niñez. Al fin he descubierto la recóndita clave de mis años, la suerte de Francisco de Laprida, la letra que faltaba, la perfecta forma que supo Dios desde el principio. En el espejo de esta noche alcanzo mi insospechado rostro eterno

(Borges 1964: 28).

El fracaso no es solamente la condición de existencia del texto de Mairal (empieza con las efemérides del 19 y 21 de diciembre de 2001) sino el espacio fértil donde la identidad nacional encuentra su cifra secreta, ahí donde se funda y late, donde, por fin, encuentra «su insospechado rostro eterno».

La novela termina con un barco que se lleva a María hacia Europa. En el final, no queda nada, sólo un lugar vacío y, del otro lado del océano, una mujer en una biblioteca que representa la figura de un nostos que ha fracasado en su esencia más profunda: regresar. En este caso, como hemos visto, la identidad nacional se deja respirar en el vértice exacto donde se articula el fracaso y el sentido secreto que se revela júbilo en ese fracaso. Es decir que el nostos argentino es la figura del que no puede volver. Una identidad que encuentra su esencia en el fracaso, pero que no es totalmente negativa porque es también la forma más cabal, más perfecta de la nostalgia, la pérdida más oscura, la pérdida consumada.

Entonces aparece lo único que permanece: la literatura. Contra el fracaso, la palabra. O es la palabra la que hace del fracaso un destino de júbilo secreto. Es a través del lenguaje que se puede construir una identidad de corte romántico y matriz paradojal. Una vez que el fracaso ha arrasado con todo, entonces se instala la nostalgia, entonces aparece el lenguaje como una posibilidad de vida después de la muerte, porque si se puede nombrar se puede volver. 
Cobra otro valor la insistencia por el nombre que marca los primeros capítulos de la novela, esa premura por nombrar con nombre propio lo que ahora sabemos que al final de la novela va a haber desaparecido del mapa:

Miré las estaciones pasar como si viera todo por última vez: San Isidro, Acassuso, Martínez, los árboles enormes, mi colegio, los jardines abandonados, La Lucila, Olivos, los depósitos, Vicente López, Saavedra, los playones de los supermercados; después Núñez, Belgrano, los caserones antiguos, Lisandro de la Torre, los caballos vareándose en las pistas laterales del hipódromo, las canchas de tenis, los edificios altos, y la llegada cada vez más lenta hasta Retiro (9).

En la potencia evocadora del lenguaje se enarbola la esperanza del nostos que no puede regresar a un lugar que ya no existe pero sí lo puede nombrar. Contra el fracaso, una vez que se lo ha llevado todo, que ha borrado al país de los mapas, aparece el relato, aparece la novela:

Tengo que decir frases que había perdido y que ahora reaparecen y me ayudan a cubrir el pastizal, a superponer la luz de mi lengua natal sobre esta luz traducida donde respiro cada día. Y es como volver sin moverme, volver en castellano, entrar de nuevo a casa. Eso no deshizo, no se perdió; el desierto no me comió la lengua. Ellos están conmigo si los nombro, incluso las Marías que yo fui, las que tuve que ser, que logré ser, que pude ser. Las agrupo en mi sueño donde todo está a salvo todavía (8).

\section{Bibliografía}

Borges, Jorge Luis, 1964, El otro, el mismo, Buenos Aires, Emecé.

Mairal, Pedro, 2010, El año del desierto, Madrid, Editorial Salto de Página, colección "Púpura".

Martínez Estrada, Ezequiel, 1969, Leer y escribir, México, Joaquín Mortiz S.A.

Prieto, Adolfo, 2003, Los viajeros ingleses y la emergencia de la literatura argentina 1820-1850, Buenos Aires, Fondo de cultura económica.

Sarmiento, Domingo Faustino, 2000, Facundo. Civilización y barbarie, Buenos Aires, Colihue. 